IZA DP No. 9093

The Long-term Health Effects of Fetal Malnutrition: Evidence from the 1959-1961 China Great Leap Forward Famine

Seonghoon Kim Belton M. Fleisher Jessica Ya Sun

June 2015 


\title{
The Long-term Health Effects of Fetal Malnutrition: Evidence from the 1959-1961 China Great Leap Forward Famine
}

\author{
Seonghoon Kim \\ Singapore Management University \\ Belton M. Fleisher \\ Ohio State University, CHLR, CUFE and IZA \\ Jessica Ya Sun \\ Singapore Management University
}

Discussion Paper No. 9093

June 2015

IZA

P.O. Box 7240

53072 Bonn

Germany

Phone: +49-228-3894-0

Fax: +49-228-3894-180

E-mail: iza@iza.org

\begin{abstract}
Any opinions expressed here are those of the author(s) and not those of IZA. Research published in this series may include views on policy, but the institute itself takes no institutional policy positions. The IZA research network is committed to the IZA Guiding Principles of Research Integrity.

The Institute for the Study of Labor (IZA) in Bonn is a local and virtual international research center and a place of communication between science, politics and business. IZA is an independent nonprofit organization supported by Deutsche Post Foundation. The center is associated with the University of Bonn and offers a stimulating research environment through its international network, workshops and conferences, data service, project support, research visits and doctoral program. IZA engages in (i) original and internationally competitive research in all fields of labor economics, (ii) development of policy concepts, and (iii) dissemination of research results and concepts to the interested public.
\end{abstract}

IZA Discussion Papers often represent preliminary work and are circulated to encourage discussion. Citation of such a paper should account for its provisional character. A revised version may be available directly from the author. 


\section{ABSTRACT \\ The Long-term Health Effects of Fetal Malnutrition: Evidence from the 1959-1961 China Great Leap Forward Famine*}

We report evidence of long-term adverse health impacts of in utero exposure to malnutrition based on survivors in their 50 s who were born during the China Famine that occurred in the years 1959-1961. We take advantage of recently available data provided by the China Health and Retirement Longitudinal Study (CHARLS) to corroborate evidence supporting the Fetal Origin Hypothesis. We find that fetal exposure to malnutrition has large and long-lasting impacts on both physical health and cognitive abilities, including the risks of suffering a stroke, physical disabilities in speech, walking and vision, and measures of mental acuity. Our findings on the health impacts of fetal malnutrition on middle-age survivors suggest that it would be desirable to trace the changes of health status of the famine survivors as they age into later life stages. We suspect that such further study would support the lifetime benefits of in utero and early infancy health interventions that extend through the life cycle in the form of avoiding both physical and mental impairment.

JEL Classification: I10, I12, J14

Keywords: fetal origin hypothesis, malnutrition, health, China Famine

Corresponding author:

Belton M. Fleisher

Department of Economics

The Ohio State University

1945 North High Street

Columbus, $\mathrm{OH} 43210$

USA

E-mail: fleisher.1@osu.edu

\footnotetext{
* We thank Tomoki Fujii, participants of a seminar at Université Paris Dauphine, and participants of 2015 Singapore Health Economics Association Conference for valuable comments.
} 


\section{Introduction}

Malnutrition among pregnant women and children has been a long-standing problem in developing countries. For example, China, though achieving impressive economic development, still has more than 120 million individuals suffering from malnutrition and 7.2 million children with stunted growth (Chen, 2013). The "Fetal Origins Hypothesis" of Barker (1992) and much subsequent work argue that fetal malnutrition "programs" the fetus with metabolic characteristics that can lead to future diseases. In the absence of human-subject randomized controlled experiments that might establish a causal link between fetal malnutrition and later life health outcomes, historical events such as the Dutch Famine of 1944 (Roseboom et al., 2001; Scholte et al., 2015) have provided researchers with data permitting the study of the long-term effects of fetal malnutrition. The 1959-1961 China Great Leap Forward Famine (hereafter China Famine), being the worst famine in human history, caused about 30 million excess deaths (Li and Yang, 2005). The dramatic differences in famine intensity across cohorts and regions make the China Famine a particularly well-suited quasi-natural experiment to identify the causal influences of fetal exposure to malnutrition.

We contribute to the literature by examining the long-term health effects of fetal malnutrition in a sample of China Famine survivors surveyed when they were in their 50s. Studies have shown that infants who experienced malnutrition during the fetal period may be born with normal birth weight and birth size but appear to suffer from various diseases, such as cardiovascular diseases, diabetes, and breast cancer in later stage of life because the initial adaptations of DNA to help the survival of a fetus can trigger health problems in later adulthood (Scholte et al., 2015; Lumey et al., 2011; Schulz, 2010). For example, the Dutch Famine studies suggest that the adverse influences of in utero exposure to malnutrition on cognitive abilities become obvious when survivors turned into their 50s, while no significant effects were seen during their 20s (Stein et al., 1972; Scholte et al., 2015). The delayed effects of prenatal influences are likely to have prevented earlier studies of the China Famine from identifying the full negative consequences of fetal malnutrition, because the age range of famine victims in earlier studies was, necessarily mainly younger than 40 years of age.

Half a century after the event, we are now able to examine the long-term impacts of in utero malnutrition on health outcomes of the survivors in their middle age with newly available 
nationwide panel data on the Chinese elderly, the China Health and Retirement Longitudinal Study (CHARLS). CHARLS is a biannual panel survey that began in 2011 and collects rich information on a wide array of detailed objective and subjective health measures of a representative national sample of individuals who were aged 45 and over in China. CHARLS has much richer information on various health measures than the China Population Census data and has a much larger sample compared to the China Health and Nutrition Study (CHNS) data.

There are several studies on the health effects of the China Famine, but they use relatively simple measures such as heights and weights observed at early adulthood (Gorgens et al., 2007; Chen and Zhou, 2007; Meng and Qian, 2009; Fung and Ha, 2010), or look at other health measures using a limited sample (e.g., data obtained from a local hospital) (Clair et al., 2005; Xu et al., 2009). There has been little, if any, comprehensive evaluation of the occurrence and magnitude of long-term health consequences of the China Famine, and the newly available CHARLS data allow us to evaluate these outcomes.

We identify the long-term health effects of fetal malnutrition using province-specific and year-specific death rates weighted by birth month as a proxy for the famine severity. We find that fetal exposure to the China Famine of individuals born during 1959-1961 had led to a 24.3\% greater likelihood of developing speech impediment, a $12 \%$ greater likelihood of suffering difficulty in walking and a $3.3 \%$ greater chance of developing vision impairment later in life compared to individuals who were born before or after the China Famine. We also find that survivors who experienced the famine in utero have a higher probability of having suffered from a stroke compared to non-famine cohorts.

Consistent with the findings of the Dutch Famine studies, our results show that the survivors of the China Famine are likely to have a higher probability of low cognitive function. Survivors who experienced the famine in utero tend to perform much worse in terms of performing simple arithmetic calculations and date recall tests. Since pregnancy is the critical period of time when the nervous system is being developed and the human body of the pregnant women prioritizes the survival of a fetus over brain development, malnutrition experience during 
the gestation can cause defects in the formation of famine survivors' neural system (Schulz, 2010). ${ }^{1}$

The remainder of the paper is structured as follows. In Section II, we briefly discuss the background of the 1959-1961 China Famine and review the related literature. Section III lays out our empirical strategy for estimating the long-term effects of fetal malnutrition on physical and cognitive outcomes. In section IV, we describe the data and report sample statistics. Section V presents the estimation results and discusses our findings. Section VI concludes.

II. Brief background and related literature on the 1959-1961 Great Leap Forward Famine

In 1958, the Chinese Communist Party implemented a set of nationwide policies, known as the Great Leap Forward (GLF) Movement, aiming to quickly catch up the level of industrialization of the Soviet Union and the United States. Available resources were diverted from the agriculture sector to the manufacturing sector, and the central government sharply increased grain procurement from the rural population for urbanization and export. The excessprocurement of grain from rural areas, exacerbated by a series of severe weather conditions, led to a huge decrease in caloric intake of rural residents and thus to their physical capacity to engage in farm work. As a result, grain production dropped substantially, leading to a vicious cycle of malnutrition, lowered labor productivity and further reductions in output of agricultural products worsened by reduced production incentives (Meng and Qian, 2009).

Compared to the pre-famine production level, national grain output dropped by almost 30\% in 1960 (Li and Yang, 2005). Exacerbating the impact of lower agricultural production, the Chinese central government's delayed response to the food shortage, severe limitations on interregional transfer of grain and other foods, transfer of food to the industrial sector's workers, and ignorance of local conditions (due in part to politically motivated over-reporting of grain output) all contributed to turning the overall reduction in food availability into the 1959-1961 China Famine, probably the worst famine in human history as measured by excess deaths.

\footnotetext{
${ }^{1}$ Animal studies are also in line with our finding. For example, previous lab experiments on rodents show that deced ents of undernourished mother rats tend to have fewer brain cells than decedents of normally nourished mother rats ( Strauss, 1997)
} 
Scholars estimate that the China Famine resulted in approximately 23-30 million deaths above what might have been expected under normal grain production and distribution and 30 million lost births (Chen and Zhou, 2007).

Although the China Famine was a national phenomenon, the famine intensity varied significantly across provinces (Chen and Zhou, 2007). For example, central provinces such as Henan, Anhui and Sichuan were extremely severely affected by the famine, but the northeastern provinces were less severely impacted (Almond et al., 2010). Figure 1 shows the number of excess deaths during the famine period and its geographical variation.

The Chinese central government eventually recognized the severity of the famine and moderated its policies, reducing the transfer of grain from rural areas to urban areas and sending millions of people back to the countryside to boost agricultural production, raising the rural labor force by more than 50 million ( $\mathrm{Li}$ and Yang, 2005). By 1961, death rates began to come back to the pre-1959 level in over half of the provinces, and birth rates started to rebound as shown in Figures 1 and 2.

\section{$\underline{\text { Related Literature }}$}

Most existing studies of the lasting impacts of the China Famine have focused on economic outcomes such as labor supply, income or education attainment (Meng and Qian, 2009; Chen and Zhou, 2007; Shi, 2011; Almond et al., 2010; Kim et al., 2014). Compared to the non-famine cohorts, those born during the China Famine tend to work fewer hours, are more like to be illiterate, and to marry a spouse with less education (Almond et al., 2010). Existing research has also found that the famine's impacts are not limited in the first generation. Children who were born to famine survivors tend to have fewer years of schooling, higher BMI and stunted heights (Fung and Ha, 2010; Kim et al., 2014; Tan et al., 2014). Studies regarding the China Famine's impacts on health outcomes are relatively limited due to the availability of the data. Only simple health measures such as height, weight and BMI were examined at relatively young ages (20s-30s) (Chen and Zhou, 2007; Meng and Qian, 2009; Fung and Ha, 2010). It was shown that fetal exposure to malnutrition is associated with significant reduction of height and body weight (Chen and Zhou, 2007; Meng and Qian, 2009). Though height and weight are indicators of famine survivors' health conditions, they provide very rough references for understanding the famine's influences on detailed health outcomes such as hypertension, 
cognitive abilities, mental functions and other specific health conditions. Our study of the China Famine is an effort to fill the gap by examining a rich set of health outcomes and providing references to understand fetal malnutrition's long lasting impacts in famine survivors' middle age.

Particularly, for mental health, previous studies have focused mainly on fetal malnutrition's impacts on the probability of suffering from schizophrenia. Consistent with the Dutch Famine studies, exposure to malnutrition in utero could lead to higher risk of schizophrenia in survivors' early adulthood. However, the data for these studies tend to be restricted to narrow geographical areas. For example, Clair et al. (2005) and Xu et al. (2009) use local hospital records from Anhui and Guangxi autonomous region and thus cannot control for region-specific heterogeneity.

\section{Econometric Specification and Empirical Strategy}

Our econometric model is represented by the following equation:

$$
\text { (1) } Y_{i p t k}=\beta W D R_{p t k}+\gamma X_{i p t k}+\mu_{p}+\delta_{t}+\phi_{k}+\varepsilon_{i p t k}
$$

where the subscript $i$ represents an individual, $p$ a birth province, $t$ a birth year and $k$ a birth month. We use the province-year level death rate weighted by months in utero during birth year $\mathrm{t}$ and year $t-1$ as a measure of fetal exposure to malnutrition, following Almond et al. (2010). For example, an individual born in January 1960 in Shandong would be assigned 1/9th of Shandong's 1960's average death rate (ADR) and 8/9th of Shandong's 1959's average death rate; for individuals born in September to December, the weighted death rate is the same as the birth year's average death rate, because conception occurred in the year of birth. It follows that for those born in months January through August, i.e., $k=1, \cdots, 8$,

(2) $W D R_{p t k}=\frac{k}{9} \times A D R_{p t}+\frac{9-k}{9} \times A D R_{p, t-1}$

where $A D R$ is the province- and year- specific measure of famine intensity, equivalent to the number of deaths per 1,000 individuals in year $t$ and province $p . X$, a vector of controls, include other characteristics that might affect current health outcomes such as gender and father's and mother's education. In the regression, we control for permanent unobserved province-specific heterogeneity, $\mu_{p}$, year-specific unobserved heterogeneity invariant across provinces, $\delta_{t}$, and month-specific unobserved heterogeneity, $\phi_{k}$. In the absence of confounding factors, $\hat{\beta}$ can be 
interpreted as the estimated causal effect of fetal exposure to the China Famine on health outcomes.

The following discussion deals with potential confounding factors that would lead to biased estimation of $\hat{\beta} .^{2}$

\section{$\underline{\text { Selective Mortality }}$}

The most severely impacted individuals are more likely to have died during or shortly after the famine. Also, since the China Famine took place over half a century ago, those severely impacted individuals who managed to survive birth and early life are less likely to have survived into middle age. As a result, the famine survivors in our sample would be in general healthier than the famine victims who are missing due to selective deaths. We do not have any information about those who are missing due to the famine-caused deaths, so we cannot correct for this bias. However, since selective mortality makes our estimates biased toward zero effect, our estimates of the long-run health impacts of the fetal experience to the China Famine can be interpreted as lower bounds of the true effects.

\section{Selective Fertility}

Due to the extreme adverse environmental and nutritional conditions during the China Famine, marriages and childbearing were postponed or foregone through choice and reduced chance of conceiving. Shi (2011) reports that there were about 15 million lost births due to the China Famine. Therefore, children born during the famine would have come from families with better socio-economic and nutritional conditions. Similar to the bias caused by selective mortality, selective fertility during the famine period biases estimated effects of fetal experience to the China Famine toward zero.

Moreover, parents whose childbearing was delayed by the famine appear to have offset the birth-rate dip after the famine ended. Figure 2 reveals a sharp increase in birth rates in 1962 , the year after the famine ended. To the extent that the post-famine surge in birth rates is attributable to women whose health was impaired by the famine, it is likely that children born right after the famine inherited characteristics attributable to the famine. Thus, the two fertility

\footnotetext{
${ }^{2}$ The discussion of econometric issues in estimating the long-run health impacts of early-life malnutrition is largely taken from Kim et al. (2014).
} 
selections (positive selection during the famine and negative selection right after the famine) would attenuate the estimated in utero impacts of the China Famine on long-run health outcomes toward no effect.

\section{$\underline{\text { Selective Migration }}$}

The intensity of the China Famine varied greatly across provinces. Central provinces were the worst hit while northeastern provinces were relatively spared (Almond et al., 2010). Migration from severely impacted areas to less impacted regions was virtually prohibited before 1978. According to Chen and Zhou (2007), interprovincial migration accounted for only 0.3$0.7 \%$ of the population at risk between 1959 and 1963.

\section{Measurement Error}

We acknowledge that WDR is not a perfect measure of fetal malnutrition. A pregnant woman's caloric intake would be a much better measure, but such data is not available. Thus, we argue that WDR is the best available source of the information on the fetal malnutrition shock during the China Famine. Assuming that fetal malnutrition is a stochastic function of WDR, we use $W D R$ as a proxy for the degree of fetal malnutrition.

Formally, we can write that

$$
\text { (3) } W D R_{p t k}=\delta C a l_{p t k}+\omega_{p t k}
$$

where $\mathrm{Cal}$ is the average fetal caloric intake during pregnancy, $\delta$ is a proportionality coefficient, $\omega$ is a classical type of measurement error unobserved to an econometrician. Assuming the presence of classical measurement error, we interpret our estimate of WDR as biased toward zero; thus we estimate a lower bound of the true famine effect on long-run health outcomes.

\section{Other Omitted Variables}

One might be concerned that our estimates of the fetal malnutrition impacts are confounded by the 1966-1976 Cultural Revolution's adverse influences. However, the Cultural Revolution was mainly an urban phenomenon while the China Famine was mainly confined to rural areas, and we believe that we can ignore its impacts in this study.

We control for the local institutional quality differences in policies that contributed to health through a province-fixed effect to the extent that such institutional differences are time- 
invariant. Differences across provinces in policies adopted after the China Famine could lead to biased estimation, and the direction of the bias would depend on the nature of such differential policy responses, if any. We are not aware of systematically different post-famine policy changes across provinces (Meng and Qian, 2009).

\section{Data}

The China Health and Retirement Longitudinal Study is a biannual longitudinal survey that collects rich information on economic, health, and social conditions for a representative sample of individuals who are 45 and over (as of 2011) in China. CHARLS covers 150 counties in 28 provinces, and the sample size of the baseline survey is 17,692 individuals (8471 men and 9221 women) in 10,257 households. ${ }^{3}$ The first baseline survey was conducted in 2011-2012 and the second one in 2013.

CHARLS's advantages for our research include that (i) it provides a wide array of measures of health and other individual and family characteristics, and that (ii) it focuses on the middle-age and older population, thus providing an adequate sample to study long-term health effects. By comparison, the China Population Census would be the best available data in terms of sample size, but the Census asks very little information on health (a single question on selfreported health status). The China Health and Nutrition Survey contains comparable information, but its effective sample size for our research is significantly smaller than that of CHARLS, because it surveys only 9 provinces and covers all age ranges. ${ }^{4}$ The China Household Income Project survey, an individual-level repeated cross-sectional data surveys only the urban population, while our focus is on those born in rural areas. Thus, we argue that CHARLS is the most suitable data available for our study.

We construct the sample using the following criteria. First, we select those who were born from 1954 to 1966, five years before and after the China Famine, to include substantial timevariation in our measure of in utero nutrition. Second, we restrict the sample to those born in the

\footnotetext{
${ }^{3}$ Tibet is excluded from sampling.

${ }^{4}$ Also, the CHNS does not track survey participants who migrate out of the province of the initial interview so it can potentially create a sample selection bias due to the different likelihood of migration by ability and health.
} 
rural areas because the famine took place mostly in the rural areas. We drop individuals from the provinces where provincial death data are not available. ${ }^{5}$

Figure 3 shows that the size of the cohorts between 1959 and 1961 is much smaller than before or after this period, reflecting the increased death rate and the lowered birth rate resulting from the famine severity. We observe a continuing drop in the number of sample individuals starting in 1958, and then a sharp rebound after 1961. The frequency of each sample cohorts closely mirrors the distributions in birth and death rates in China from 1954 to 1966.

Sample statistics are reported in Table 1. The final sample size after imposing the above selection criteria is $7276.53 \%$ of the sample is female, and $94 \%$ of the sample is married. The education level of the sample individuals is much higher than that of their parents: more than $80 \%$ of the sample completed primary school while only $43 \%$ of their fathers and $15 \%$ of their mothers reached this level. The surveyed households on average have 3.45 family members. There is wide dispersion in the distribution of annual income and working hours. The mean of annual income is 13,531 yuan with a standard deviation of 31,004. The mean of the annual working hours is 366 with a standard deviation of 372 . For physical disability measures, i) $0.7 \%$ of the sample has a speech impediment, ii) $5.9 \%$ of the respondents report vision disability, and iii) $5.0 \%$ experienced difficulty in walking. $1.3 \%$ of the sample reports that they ever had a stroke. The size of the sample with cognitive problems is much larger: almost half of the sample made mistakes in carrying out simple arithmetic tasks and $58 \%$ of the respondents recall the dates (such as day of the week and month) incorrectly.

\section{Results}

Table 2 presents our estimation results reporting the effect of fetal exposure to the China Famine on survivors' health conditions. Standard errors are clustered at the province level and reported in parentheses. Note that all specifications include father's and mother's education and fixed effects for birth year, birth month, and birth province. We also include a female dummy

\footnotetext{
${ }^{5}$ Chongqing was previously a part of Sichuan but became a direct-controlled municipality in 1997. Therefore, there are no separate provincial death data for Chongqing.
} 
variable to account for potential gender differences. ${ }^{6}$ As discussed in the previous section, we interpret the estimated coefficient of $W D R$ as a lower bound of the magnitude of the negative long-term health effects of fetal malnutrition. The coefficients reported in Table 2 represent the marginal effect of a unit change in $W D R^{*} 1000$ on the probability of a corresponding dependent variable of interest evaluated at the mean of $W D R .^{7}$ In order to show economic significance of the famine impact, we also report the effect of one standard deviation of WDR on the probability of a corresponding dependent variable in square brackets. ${ }^{8}$

\section{A. Regression Results}

As hypothesized, in utero exposure to the China Famine has had large and long-lasting impacts on survivors' physical health and cognitive abilities. Column (1) of Table 2 shows that a one standard deviation increase of famine intensity resulted in a 0.17 percentage-point increase in the probability of a speech impediment, which is a $24.3 \%$ increase in the likelihood of suffering from this disability compared to the average.

Column (2) reports the famine impact on respondents' evaluations of whether they have any trouble walking longer than 100 meters. A one standard deviation increase of famine intensity is associated with a 0.6 percentage-point increase in the probability of difficulty of walking, or about $12 \%$ increase in the likelihood of experiencing this disability compared to the average.

Column (3) further confirms the causal relationship between fetal exposure to famine and physical disability: a one-standard deviation increase of famine intensity increases the probability of developing vision disabilities by a 0.2 percentage-point increase or a $3.3 \%$ increase in the likelihood compared to the average. Disabilities in speech, vision and difficulty in walking could not only be viewed as direct health consequences of prenatal exposure to malnutrition, but also complications of other health problems such as stroke. Therefore, we could

\footnotetext{
${ }^{6} \mathrm{We}$ also included an interaction term between $W D R$ and a female dummy to capture the gender-specific famine impact on health outcomes, but the statistical significance and economic magnitude of the interaction term for all outcome variables is close to zero, so we only report results using a female dummy variable as a control.

${ }^{7}$ Sample size varies across different outcome variables due to the missing values in the corresponding outcome varia bles. However, our results are robust even if we use the identical sample across different outcome variables (i.e., the sample without no missing values for all outcome variables).

${ }^{8}$ One standard deviation of WDR is approximately equal to the difference of average WDR between famine years and non-famine years.
} 
interpret the results of columns (1) to (3) as reflections of adverse impacts of fetal exposure to malnutrition on survivors' general physical health.

It has been reported that prenatal exposure to malnutrition negatively impacts survivors' cognitive abilities (Barker, 1992). Thus, we examine the relationship between fetal malnutrition and cognition outcomes. In CHARLS, respondents were asked to perform a series of simple arithmetic calculation tests and a date check test. Defining a failure to satisfy either of these tasks as an error, we show in column (4) that a one standard deviation increase of famine intensity resulted in a 1.8 percentage-point increase in the probability of a speech impediment, which is a $4.2 \%$ increase in the likelihood of error in the calculation test; in column (5) we see that a standard deviation increase in WDR leads to a 1.2 percentage-point increase in the probability of not knowing the correct survey date (such as day of the week, month of the survey, etc.), which is a $2.1 \%$ increase in the likelihood of recall error. Interestingly, coefficient estimates on the female dummy are significant on both measures. On one hand, it indicates potential gender differences in impacts from fetal exposure to famine on cognitive functions. On the other hand, it could also reflect the gender differences in education attainment in China. Due to preference for boys, females in general receive less education than males and thus may make more mistakes in tasks such as arithmetic calculation tests. ${ }^{9}$

Column (6) reports estimation results for the impact of in utero famine exposure to stroke. We see a one standard deviation increase of famine intensity would lead to a 0.3 percentage point increase in the probability of having had stroke, which amounts to a $23.1 \%$ increment of risk compared to the mean. This finding shows significant influences of adverse prenatal environment on survivors' cerebrovascular health.

Our results confirm many findings of the previous literature regarding the damaging effects of in utero exposure to malnutrition. However, we do not find substantial impact of famine on health measures commonly used in the China Famine literature such as height and weight as reported by Chen and Zhou (2007) and Meng and Qian (2009). ${ }^{10}$ Also, we do not find any statistically significant results for other ailments such as heart attack or hypertension while

\footnotetext{
${ }^{9}$ Consistent with our speculation, once we control for the survivor's education, the magnitudes of the coefficient estimate on female becomes much smaller or statistically insignificant. See Panel C of Table 4. However, we do not include the sample individual's own education as a control in the baseline specification because it could have been directly affected by the famine (a bad control problem).

${ }^{10}$ Since these outcomes were observed at younger ages, it is possible that some of them have died (selective mortality).
} 
many of them have correct signs. Since our sample population has only reached their middle ages, we might expect to observe more precisely estimated impacts on these health problems as individuals age further.

\section{B. Robustness Check}

To check the robustness of our findings, we first report regression results using the average death rate, $A D R$, which is the basis for constructing the weighted death rate, WDR, but is not adjusted to account for birth month. Since $A D R$ should be less accurate in capturing the intensity of the famine than $A D R$, we expect that the coefficient estimates on $A D R$ would be similar but less precise. As reported in Table 3 panel A, the estimated impacts of fetal exposure to malnutrition on speech and vision disabilities, difficulty in walking, and cognitive measures are robust to the modification of the measure of malnutrition exposure. Although the estimated impact on the probability of having had stroke loses statistical significance, its magnitude remains consistent with our baseline estimation.

Since the China Famine was mainly a rural phenomenon, running the same set of regression on the urban-born population provides another robustness check on our results, because we do not expect to find negative health effects of the China Famine on those born in urban areas. The regression results are presented in Table 3, panel $\mathrm{B}$, and we indeed find no effects of fetal malnutrition on health outcomes among urban-born members of the sample as expected.

In panel $\mathrm{C}$ of Table 3, as another robustness check, we add the sample individual's own education attainment to the baseline specification, although we acknowledge that education attainment can be partially determined by the famine exposure and is thus not an ideal control variable. As stated above, the magnitude of the coefficient estimates on the female dummy variable become smaller, especially on cognitive outcomes, when we additionally include education attainment. This could be due to the fact that lower education attainment of females (reflecting China's son preference culture) can partially explain the coefficient estimate on the female dummy variable on health outcomes, because education has positive effects on health in general. In addition, the coefficient estimates of $W D R$ are robust to the inclusion of education attainment in general suggesting that the negative long-term famine impacts are not explained by differences in education levels. 
Finally, in an attempt to eliminate a potential source of attenuation bias and omitted variable bias, we estimate equation (1) using the 2SLS procedure. WDR is instrumented by province- and year- specific weather conditions (Li and Yang, 2005). ${ }^{11}$ The identifying assumption is that bad weather is orthogonal to unobserved heterogeneity correlated with WDR. The probit-IV estimation results are shown in Table 3, panel D. Unfortunately, the coefficients on WDR are not precisely estimated and thus the results are not informative.

\section{Conclusion}

We report evidence of long-term adverse health impacts of fetal malnutrition based on survivors in their 50s who were born during the 1959-1961 China Famine. Our results support the Fetal Origins Hypothesis (Barker, 1992) that in utero shocks can alter the activities of the epigenome $^{12}$ in favor of survival, but only at the cost of a higher probability of developing certain diseases in later life stages. We find that fetal exposure to malnutrition has large and longlasting impacts on both physical health and cognitive abilities, including the risks of suffering from a stroke, physical disabilities in speech, walking and vision, and measures of mental acuity. Our findings on the health impacts of fetal malnutrition on middle-age survivors suggest that it should be desirable to trace the changes of health status of the famine survivors as they age into later life stages.

Our study provides evidence supporting policies and programs to improve the nutritional status of pregnant women. As implied by one of the United Nations' Millennium Development Goals, maternal health has received increasing attention in recent years. For example, Improving Nutrition and Food Safety for China's Most Vulnerable Women and Children, a joint program of the United Nations and the Chinese central and local governments has focused on food-related issues of 1.2 million children, women of childbearing age and other at risk populations. It aims to reduce mortality and other adverse impacts of malnutrition by providing nutritional packages to children and pregnant women (Chen, 2013). Our findings imply that the payoff to such

\footnotetext{
${ }^{11}$ We adopt weather information as an instrument because the three-year famine period coincided with bad weather. The 1959-61 China Famine was officially named as "Thee Years of Natural Calamities", quoting the bad weather as the major blame for the catastrophe by the Chinese government.

${ }^{12}$ Epigenome can be viewed "a series of switches that cause various parts of the genome to be expressed or not" (Almond and Currie, 2011).
} 
interventions play out much further into the future than evaluation of their immediate benefits might suggest. 


\section{References}

Almond, Douglas, Lena Edlund, Hongbin Li, and Junsen Zhang. 2010. "Long-term Effects of the 1959-1961 China Famine: Mainland China and Hong Kong." In The economic consequences of demographic change in East Asia, NBER-EASE Vol.19, eds. T.Ito and A. Rose, 321-50. Chicago: University of Chicago Press.

Almond, Douglas, and Janet Currie. 2011. "Killing Me Softly: The Fetal Origins Hypothesis." Journal of Economic Perspectives, 25(3): 153-72.

Barker, David J. P. 1992. "Fetal and Infant Origins of Adult Diseases." British Medical Journal, 301(6761).

Chen, Jie, 2013. "Joint Programme on Improving Nutrition, Food Safety and Food Security for China's Most Vulnerable Women and Children Final Evaluation Report." MDG Achievement Fund in China.

Chen, Yuyu, and Li-An Zhou. 2007. "The Long-term Health and Economic Consequences of the 1959-1961 Famine in China." Journal of Health Economics, 26(4):659-81.

Clair, David, Mengqing Xu, Peng Wang, Yaqin Yu, Yourong Fang, Feng Zhang, Xiaoying Zheng, Niufan Gu, Guoyin Feng, Pak Sham, and Lin He, 2005. "Rates of Adult Schizophrenia Following Prenatal Exposure to the Chinese Famine of 1959-1961." JAMA, 294(5): 557-62.

Fung, Winnie, and Wei Ha. 2010. "Intergenerational Effects of the 1959-61 China Famine." In Fuentes-Nieva, \& Seck (Eds.), Risk, shocks and human development: On the brink, 222-254. London: Palgrave-Macmillan.

Gorgens, Tue, Xin Meng, and Rhema Vaithianathan. 2007. "Stunting and Selection Effects of Famine: a Case Study of the Great Chinese Famine." Journal of Development Economics, 97(1):99-111.

Kim, Seonghoon, Quheng Deng, Belton M. Fleisher, and Shi Li. 2014. "The Lasting Impact of Parental Early Life Malnutrition on Their Offspring: Evidence from the China Great Leap Forward Famine.” World Development, 54: 232-242.

Meng, Xin, and Nancy Qian. 2009. "The Long-term Consequences of Famine on Survivors: Evidence from a Unique Natural Experiment using China’s Great Famine.” NBER Working paper No.14917. 
Meng, Xin, Nancy Qian, and Pierred Yard. 2014 "The Institutional Causes of China's Great Famine, 1959-1961.” NBER Working paper No.16361.

Li, Wei, and Dennis Tao Yang. 2005. "The Great Leap Forward: Anatomy of a Central Planning Disaster." Journal of Political Economy, 113 (4).

Lumey, L.H, Aryeh D. Stein, and Ezra Susser. 2011. "Prenatal Famine and Adult Health." Annual Review of Public Health, 32: 237-62.

Roseboom, Tessa J, Jan H.P. Meulen, Anita C. J. Ravelli, Clive Osmon, David J. P. Barker, and Otto P. Bleker. 2001. "Effects of Prenatal Exposure to the Dutch Famine on Adult Diseases in Later Life: An Overview.” Twins Research, 4(5): 293-98.

Scholte, Robert S., Gerard J. Van Den Berg, and Maarten Lindeboom. 2015. "Long-Run Effects of Gestation During the Dutch Hunger Winter Famine on Labor Market and Hospitalization Outcomes." Journal of Health Economics (39): 17-30.

Schulz, L. C. 2010. "The Dutch Hunger Winter and the Developmental Origins of Health and Disease." Proceedings of the National Academy of Sciences of the United States of America, 107(39):16757-16758

Stein, Zena, Mervyn Susser, Gerhart Saenger, and Francis Marolla. 1972. "Nutrition and Mental Performance.” Science, 178(4062):708-713.

Shi, Xinzheng. 2011. "Famine, Fertility, and Fortune in China." China Economic Review, 22(2): 244-59.

Strauss, Richard. 1997. "Effects of Intrauterine environment on childhood growth." British Medical Bulletin, 53(1): 81-95.

Tan, Chih Ming, Zhibo Tan, and Xiaobo Zhang. 2014. "Sins of Father: the Intergenerational Legacy of the Great 1959-61 Chinese Famine on Children's Cognitive Development." International Food Policy Research Institute Discussion Paper No. 01351.

Xu, Mingqing, Wensheng Sun, Benxiu Liu, Yinfeng Guo, Yu Lan, Lawrence Yang, He Guang, Pak Sham, Ezra Susser, David Clair, and He Lin. 2009. "Prenatal malnutrition and adult schizophrenia: further evidence from the 1959-61 Chinese famine." Schizophrenia Bulletin, 35(3): 568-76. 
Figure 1 Severity and Geographical Variation of Annual Death Rates in China

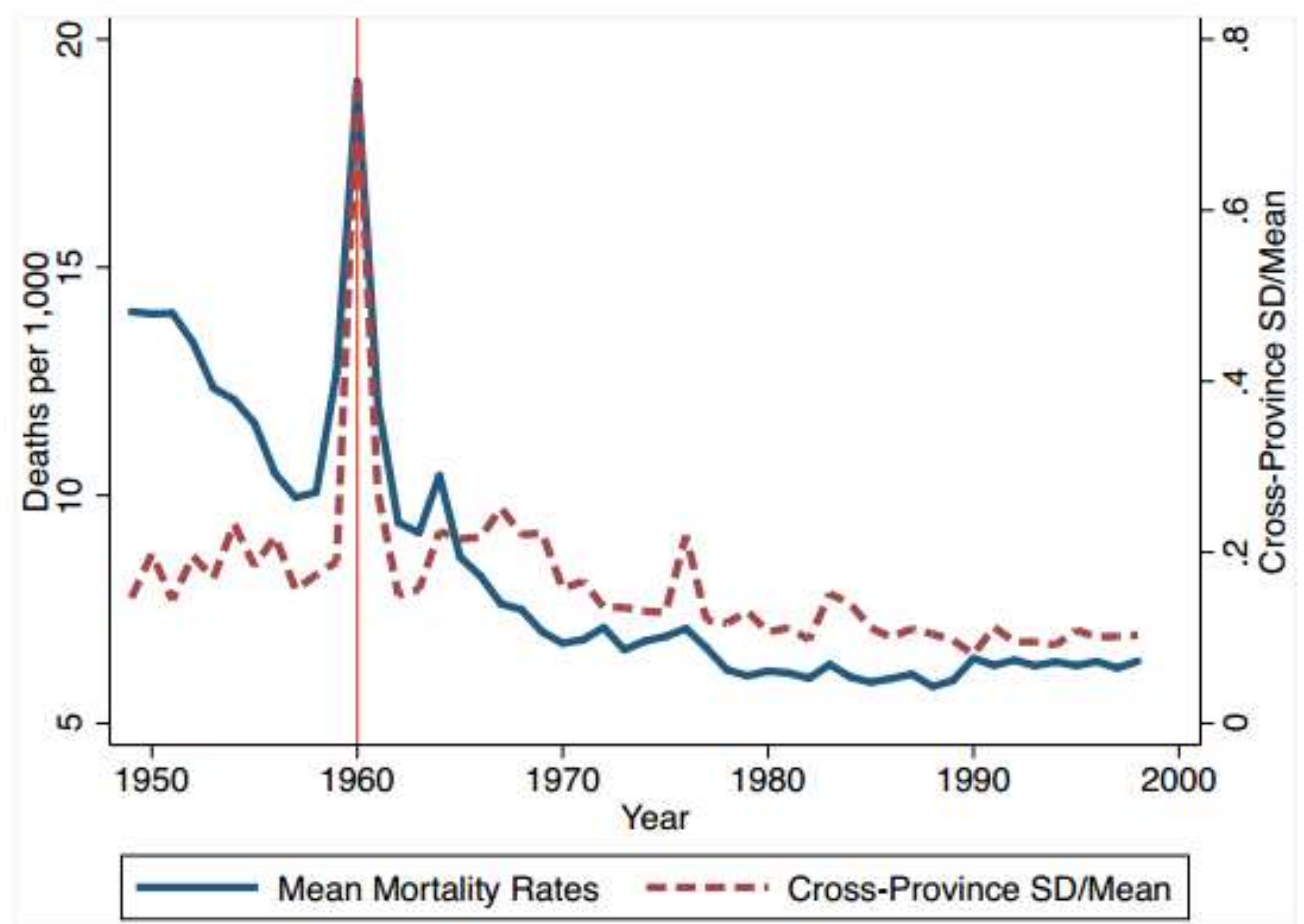

Source: Meng, Qian and Yared (2014)

Figure 2 China's Total Fertility Rate, 1954-1966

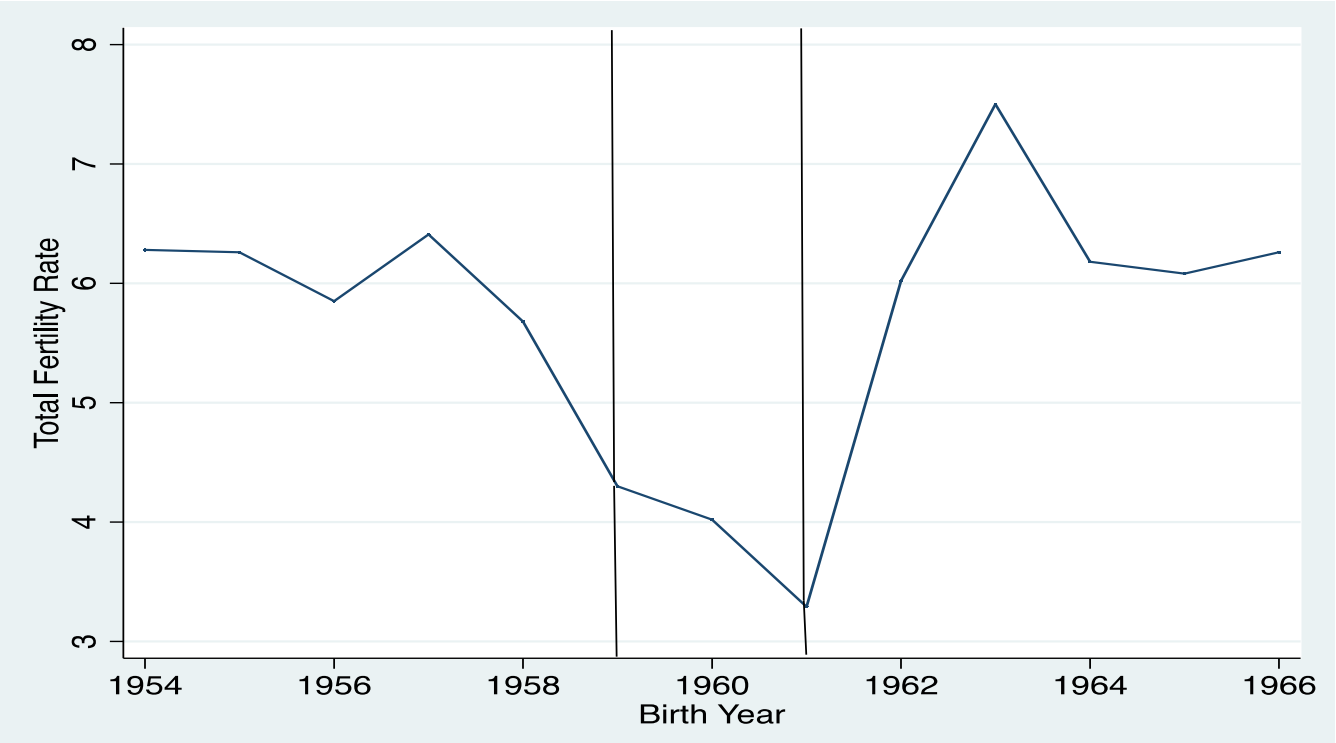

Source: China National Bureau of Statistics 
Figure 3: Frequency of Sample Birth Cohorts

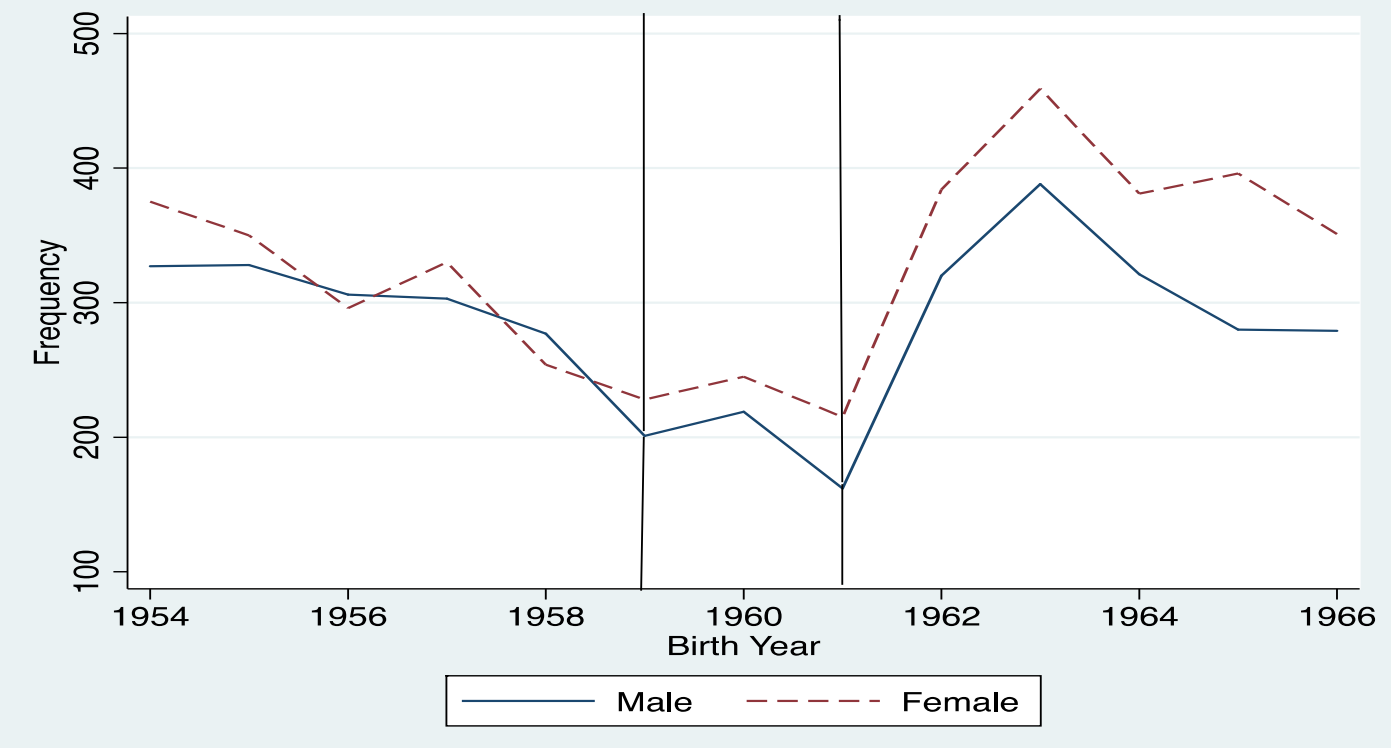

Source: Authors' calculation 
Table 1 Summary Statistics

\begin{tabular}{lccc}
\hline \hline \multirow{2}{*}{ Variable } & \multicolumn{2}{c}{ Statistics } \\
\cline { 2 - 4 } & $\mathrm{N}$ & Mean & SD \\
\hline Proportion married & 7,276 & .94 & $(.23)$ \\
Annual working hours & 7,219 & 366 & $(372)$ \\
Proportion the sample individual's & 7,276 & .43 & $(.50)$ \\
father completed primary school & & & $(36)$ \\
Proportion the sample individual's & 7,276 & .15 & $(.50)$ \\
mother completed primary school & & .53 & $(.39)$ \\
Proportion women & 7,276 & .82 & $(1.60)$ \\
Proportion the sample individual & 7,276 & 3.45 & $(31,004)$ \\
completed primary school & & 13,531 & $(.085)$ \\
Family Size & 7,276 & & $(.22)$ \\
Annual Income (in 2013 CNY) & 7,276 & .007 & $(.24)$ \\
\hline Health Outcome Variables & & .050 & $(.11)$ \\
\hline Speech Impediment & 7,231 & .059 & $(.50)$ \\
Difficulty in Walking & 7,116 & .013 & $(.49)$ \\
Vision Disability & 7,231 & .43 & .58 \\
Ever Had Stroke & 7,232 & & \\
Calculation Error & 7,232 & 7,232 & \\
Recall Error & & & \\
\hline \hline
\end{tabular}

Table 2 Regression Results

\begin{tabular}{lcccccc}
\hline \hline & $(1)$ & $(2)$ & $(3)$ & $(4)$ & $(5)$ & $(6)$ \\
& $\begin{array}{c}\text { Speech } \\
\text { Impediment }\end{array}$ & $\begin{array}{c}\text { Difficulty in } \\
\text { Walking }\end{array}$ & $\begin{array}{c}\text { Vision } \\
\text { Disability }\end{array}$ & $\begin{array}{c}\text { Calculation } \\
\text { Error }\end{array}$ & $\begin{array}{c}\text { Recall } \\
\text { Error }\end{array}$ & $\begin{array}{c}\text { Had } \\
\text { Stroke }\end{array}$ \\
\hline WDR*1000 & $0.216^{* *}$ & $1.01^{* *}$ & $0.368^{*}$ & $3.29^{* * *}$ & $2.41^{*}$ & $0.434^{*}$ \\
& $(0.086)$ & $(0.479)$ & $(0.221)$ & $(1.20)$ & $(1.27)$ & $(0.253)$ \\
& {$[0.0017]$} & {$[0.006]$} & {$[0.002]$} & {$[0.018]$} & {$[0.012]$} & {$[0.003]$} \\
Female & -0.00142 & $0.0285^{* * *}$ & 0.00356 & $0.150^{* * *}$ & $0.024^{*}$ & 0.00033 \\
& $(0.0013)$ & $(0.005)$ & $(0.0046)$ & $(0.014)$ & $(0.013)$ & $(0.0027)$ \\
Pseudo-R & 0.07 & 0.05 & 0.07 & 0.04 & 0.016 & 0.061 \\
Observations & 6,878 & 7,089 & 7,227 & 7,228 & 7,228 & 6,852 \\
\hline
\end{tabular}

Note: Standard errors clustered at provincial level are reported in parentheses. All regression results include fixed effects for birth year, birth month, birth province, and parents' education. The effects of one SD increase in WDR on the probability of outcome variables are reported in square brackets. ${ }^{* * *} \mathrm{p}<0.01,{ }^{* * *} \mathrm{p}<0.05,{ }^{*} \mathrm{p}<0.1$ 
Table 3 Robustness Analysis

A. Average Death Rate (ADR)

\begin{tabular}{ccccccc}
\hline \hline & $(1)$ & $(2)$ & $(3)$ & $(4)$ & $(5)$ & $(6)$ \\
& $\begin{array}{c}\text { Speech } \\
\text { Impediment }\end{array}$ & $\begin{array}{c}\text { Difficulty in } \\
\text { Walking }\end{array}$ & $\begin{array}{c}\text { Vision } \\
\text { Disability }\end{array}$ & $\begin{array}{c}\text { Calculation } \\
\text { Error }\end{array}$ & $\begin{array}{c}\text { Recall } \\
\text { Error }\end{array}$ & $\begin{array}{c}\text { Had } \\
\text { Stroke }\end{array}$ \\
\hline ADR*1000 & $0.202^{* * *}$ & $1.00^{* * *}$ & $0.397^{*}$ & $3.05^{* *}$ & $2.53^{* *}$ & 0.41 \\
& $(0.08)$ & $(0.46)$ & $(0.23)$ & $(1.3)$ & $(1.23)$ & $(0.25)$ \\
Female & -0.001 & $0.0285^{* * *}$ & 0.004 & $0.149^{* * *}$ & $0.024^{*}$ & 0.0003 \\
& $(0.001)$ & $(0.005)$ & $(0.005)$ & $(0.014)$ & $(0.13)$ & $(0.003)$ \\
$\mathrm{R}^{2}$ & 0.07 & 0.05 & 0.07 & 0.04 & 0.02 & 0.06 \\
Observations & 6,878 & 7,089 & 7,227 & 7,228 & 7,228 & 6,852 \\
\hline
\end{tabular}

Note: Standard errors clustered at provincial level are reported in parentheses. All regression results include fixed effects for birth year, birth month, birth province, and parents' education. ${ }^{* * *} \mathrm{p}<0.01,{ }^{* *} \mathrm{p}<0.05,{ }^{*} \mathrm{p}<0.1$

B. Urban Sample

\begin{tabular}{ccccccc}
\hline \hline & $(1)$ & $(2)$ & $(3)$ & $(4)$ & $(5)$ & $(6)$ \\
& $\begin{array}{c}\text { Speech } \\
\text { Impediment }\end{array}$ & $\begin{array}{c}\text { Difficulty in } \\
\text { Walking }\end{array}$ & $\begin{array}{c}\text { Vision } \\
\text { Disability }\end{array}$ & $\begin{array}{c}\text { Calculation } \\
\text { Error }\end{array}$ & $\begin{array}{c}\text { Recall } \\
\text { Error }\end{array}$ & $\begin{array}{c}\text { Had } \\
\text { Stroke }\end{array}$ \\
\hline WDR*1000 $^{*}$ & $-2.31^{* * *}$ & -0.978 & 1.75 & -4.10 & -1.97 & $-2.73^{*}$ \\
& $(1.14)$ & $(1.51)$ & $(1.32)$ & $(5.67)$ & $(6.33)$ & $(1.51)$ \\
Female & $-0.0126^{* *}$ & 0.008 & $-0.025^{*}$ & -0.055 & $-0.162^{* * *}$ & 0.002 \\
& $(0.006)$ & $(0.010)$ & $(0.014)$ & $(0.037)$ & $(0.033)$ & $(0.005)$ \\
Pseudo-R & 0.33 & 0.15 & 0.19 & 0.06 & 0.09 & 0.12 \\
Observations & 139 & 584 & 601 & 952 & 941 & 229 \\
\hline
\end{tabular}

Note: Standard errors clustered at provincial level are reported in parentheses. All regression results include fixed effects for birth year, birth month, birth province, and parents' education. ${ }^{* * *} \mathrm{p}<0.01,{ }^{* *} \mathrm{p}<0.05,{ }^{*} \mathrm{p}<0.1$ 
C. Inclusion of the respondents' own education as a control

\begin{tabular}{ccccccc}
\hline \hline & $(1)$ & $(2)$ & $(3)$ & $(4)$ & $(5)$ & $(6)$ \\
& $\begin{array}{c}\text { Speech } \\
\text { Impediment }\end{array}$ & $\begin{array}{c}\text { Difficulty in } \\
\text { Walking }\end{array}$ & $\begin{array}{c}\text { Vision } \\
\text { Disability }\end{array}$ & $\begin{array}{c}\text { Calculation } \\
\text { Error }\end{array}$ & $\begin{array}{c}\text { Recall } \\
\text { Error }\end{array}$ & $\begin{array}{c}\text { Had } \\
\text { Stroke }\end{array}$ \\
\hline WDR*1000 & $0.144^{* * * *}$ & $0.950^{*}$ & 0.305 & $2.95^{*}$ & $1.93^{*}$ & $0.414^{*}$ \\
& $(0.056)$ & $(0.502)$ & $(0.213)$ & $(1.59)$ & $(1.17)$ & $(0.237)$ \\
Primary School & $-0.0045^{* * *}$ & $-0.0218^{* * *}$ & -0.0891 & $-0.300^{* * *}$ & $-0.251^{* * *}$ & -0.002 \\
& $(0.001)$ & $(0.004)$ & $(0.007)$ & $(0.0237)$ & $(0.0165)$ & $(0.002)$ \\
Middle School & $-0.0067^{* * *}$ & $-0.0212^{* * *}$ & $-0.021^{* * *}$ & $-0.428^{* * *}$ & $-0.331^{* * * *}$ & $-0.007^{* * *}$ \\
& $(0.001)$ & $(0.005)$ & $(0.005)$ & $(0.0203)$ & $(0.133)$ & $(0.003)$ \\
Above Middle & $-0.0045^{* * *}$ & $-0.0277^{* * *}$ & $-0.035^{* * *}$ & $-0.521^{* * *}$ & $-0.342^{* * * *}$ & -0.0015 \\
School & $(0.0007)$ & $(0.005)$ & $(0.005)$ & $(0.018)$ & $(0.012)$ & $(0.003)$ \\
& & & & & \\
Female & $-0.0031^{* *}$ & $0.0215^{* * *}$ & -0.004 & $0.057^{* * * *}$ & $-0.057^{* * * *}$ & -0.0005 \\
& $(0.001)$ & $(0.005)$ & $(0.005)$ & $(0.014)$ & $(0.011)$ & $(0.003)$ \\
Pseudo-R & 0.13 & 0.06 & 0.08 & 0.12 & 0.1 & 0.07 \\
Observations & 6,878 & 7,089 & 7,227 & 7,228 & 7,228 & 6,852 \\
\hline
\end{tabular}

Note: Standard errors clustered at provincial level are reported in parentheses. All regression results include fixed effects for birth year, birth month, birth province, and parents' education. ${ }^{* * * *} \mathrm{p}<0.01,{ }^{* *} \mathrm{p}<0.05,{ }^{*} \mathrm{p}<0.1$

D. Probit-IV Regression

\begin{tabular}{ccccccc}
\hline & $(1)$ & $(2)$ & $(3)$ & $(4)$ & $(5)$ & $(6)$ \\
& $\begin{array}{c}\text { Speech } \\
\text { Impediment }\end{array}$ & $\begin{array}{c}\text { Difficulty in } \\
\text { Walking }\end{array}$ & $\begin{array}{c}\text { Vision } \\
\text { Disability }\end{array}$ & $\begin{array}{c}\text { Calculation } \\
\text { Error }\end{array}$ & $\begin{array}{c}\text { Recall } \\
\text { Error }\end{array}$ & $\begin{array}{c}\text { Had } \\
\text { Stroke }\end{array}$ \\
\hline WDR & -0.052 & 0.017 & -0.009 & 0.002 & 0.040 & -0.084 \\
& $(0.057)$ & $(0.040)$ & $(0.027)$ & $(0.019)$ & $(0.026)$ & $(0.066)$ \\
Female & -0.104 & 0.318 & 0.051 & 0.408 & 0.074 & 0.059 \\
& $(0.096)$ & $(0.052)$ & $(0.052)$ & $(0.037)$ & $(0.035)$ & $(0.134)$ \\
Observations & 5,178 & 5,354 & 5,437 & 5,439 & 5,439 & 5,162 \\
\hline
\end{tabular}

Note: Standard errors clustered at provincial level are reported in parentheses. All regression results include fixed effects for birth year, birth month, birth province, and parents' education. ${ }^{* * *} \mathrm{p}<0.01,{ }^{* *} \mathrm{p}<0.05,{ }^{*} \mathrm{p}<0.1$ 